\title{
Influence of the $\pi$-coordinated arene on the anticancer activity of ruthenium(II) carbohydrate organometallic complexes
}

\section{Muhammad Hanif 1,2,3, Samuel M. Meier ${ }^{2,4}$, Alexey A. Nazarov ${ }^{2,5,6}$, Julie Risse ${ }^{6}$, Anton Legin ${ }^{2}$, Angela Casini ${ }^{7}$, Michael A. Jakupec ${ }^{2,4}$, Bernhard K. Keppler ${ }^{2,4}$ and Christian G. Hartinger ${ }^{1,2,4} *^{\prime}$}

\author{
1 School of Chemical Science, The University of Auckland, Auckland, New Zealand \\ 2 Institute of Inorganic Chemistry, University of Vienna, Vienna, Austria \\ ${ }^{3}$ Department of Chemistry, COMSATS Institute of Information Technology, Abbottabad, Pakistan \\ ${ }^{4}$ Research Platform "Translational Cancer Therapy Research," University of Vienna, Vienna, Austria \\ ${ }^{5}$ Department of Chemistry, Moscow State University, Moscow, Russia \\ ${ }^{6}$ Institut des Sciences et Ingénierie Chimiques, Ecole Polytechnique Fédérale de Lausanne, Lausanne, Switzerland \\ 7 Pharmacokinetics, Toxicology and Targeting, Research Institute of Pharmacy, University of Groningen, Groningen, Netherlands
}

\section{Edited by:}

Hitoshi Ishida, Kitasato University, Japan

Reviewed by:

Anna Renfrew, The University of Sydney, Australia

Akira Odani, Kanazawa University, Japan

${ }^{*}$ Correspondence:

Christian G. Hartinger, School of Chemical Science, The University of

Auckland, Private Bag 92019,

Auckland 1142, New Zealand

e-mail: c.hartinger@auckland.ac.nz
The synthesis and in vitro cytotoxicity of a series of $\mathrm{Ru}^{\text {Il }}$ (arene) complexes with carbohydrate-derived phosphite ligands and various arene co-ligands is described. The arene ligand has a strong influence on the in vitro anticancer activity of this series of compounds, which correlates fairly well with cellular accumulation. The most lipophilic compound bearing a biphenyl moiety and a cyclohexylidene-protected carbohydrate is the most cytotoxic with unprecedented $\mathrm{IC}_{50}$ values for the compound class in three human cancer cell lines. This compound shows reactivity to the DNA model nucleobase 9-ethylguanine, but does not alter the secondary structure of plasmid DNA, indicating that other biological targets are responsible for its cytotoxic effect.

Keywords: anticancer activity, bioorganometallic chemistry, carbohydrates, phosphorus ligands, ruthenium arene compounds

\section{INTRODUCTION}

In recent years, half-sandwich $\mathrm{Ru}^{\mathrm{II}}$ (arene) complexes (Figure 1) have been shown to have promising anticancer activity that is in some cases comparable or superior to that of established anticancer drugs (Dyson, 2007; Peacock and Sadler, 2008; Hartinger and Dyson, 2009; Gasser et al., 2011; Hartinger et al., 2012). The best investigated examples of this class are $\left[\mathrm{Ru}^{\mathrm{II}}\right.$ (arene) $\left.(\mathrm{pta}) \mathrm{Cl}_{2}\right]$ (RAPTA; pta $=$ 1,3,5-triaza-7-phosphatricyclo-[3.3.1.1]decane) (Dyson, 2007), $\left[\mathrm{Ru}^{\mathrm{II}}(\text { arene })(\mathrm{en}) \mathrm{Cl}\right]^{+}$(en = 1,2-diaminoethane) (Peacock and Sadler, 2008) and $\left[\mathrm{Ru}^{\mathrm{II}}(\right.$ arene $\left.)(\mathrm{HOPO}) \mathrm{Cl}\right] \mathrm{com}-$ plexes (HOPO $=$ hydroxypyr(id)one) (Kandioller et al., 2011). The arene ligand plays a major role in the anticancer activity of ethylene-1,2-diamine compounds and related drug candidates (Habtemariam et al., 2006; Hanif et al., 2010b), while in other cases it has less impact on cytotoxicity (Mendoza-Ferri et al., 2009), unless modified with bioactive groups (Hartinger et al., 2012). Furthermore, the arene ligand imparts hydrophobic character to the molecule, which facilitates the passive diffusion through the cell membrane, enhancing the cellular accumulation. Some arene ligands facilitate the interaction of $\mathrm{Ru}$ (arene) complexes with nucleobases (Chen et al., 2003) and proteins (Casini et al., 2008). However, in general the co-ligands at the metal center determine the anticancer activity of this compound class. For example, the combination of ligands en/Cl yields a complex with activity in a xenograft model (Aird et al., 2002) while pta derivatives reduce the number and weight of metastases (Dyson, 2007).
In recent years, we have reported the development of phosphorus-substituted sugar derivatives with the aim to exploit the enhanced glucose uptake in tumors due to increased glycolytic activity in cancer cells (Berger et al., 2008; Hanif et al., 2010a, 2011, 2012a,b; Nazarov et al., 2012). These organometallic compounds exhibit selective cytotoxicity in tumorigenic cell lines, and dichlorido $\left(\eta^{6}\right.$-p-cymene) (3,5,6-bicyclophosphite-1,2$O$-cyclohexylidene- $\alpha$-D-glucofuranoside)ruthenium(II) $\mathbf{1 b}$ was found to be more cytotoxic than RAPTA-C in in vitro assays (Berger et al., 2008). The carbohydrate compounds are prone to hydrolysis, and they undergo aquation of the first halido ligand in aqueous solution, followed by hydrolysis of a $\mathrm{P}-\mathrm{O}$ bond of the phosphite ligand, and finally formation of dinuclear species (Berger et al., 2008). The aquation can be hindered or suppressed by replacing ruthenium with osmium and chlorido ligands with dicarboxylates (Hanif et al., 2010a, 2011).

Functionalizing metal-arene compounds with modified sugars should yield hybrid molecules with altered pharmacological properties, such as improved biocompatibility, bioavailability, activity and targeting potential (Gottschaldt and Schubert, 2009). Furthermore, the biophysical characteristics of compounds are significantly modified by attaching carbohydrate moieties to metal-arene units (Hartinger et al., 2008). In order to study the effect of the arene ligand on anticancer potency, a series of new $\mathrm{Ru}^{\mathrm{II}}$ (arene) complexes bearing carbohydrate-derived phosphite ligands was prepared and compared to structurally related RAPTA derivatives, also with regard to their cathepsin B inhibitory 


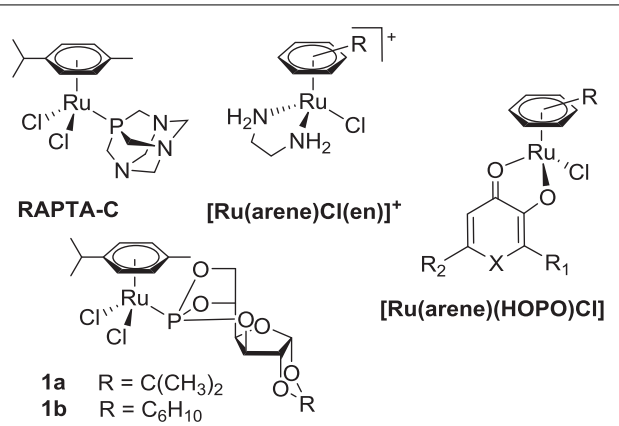

FIGURE 1 | Structures of selected Ru"(arene) anticancer complexes.

activity, which is a potential target for anticancer metallodrugs (Fricker, 2010).

\section{MATERIALS AND METHODS MATERIALS}

All chemicals were obtained from commercial suppliers and used as received and were of analytical grade except for methanol and $\mathrm{CH}_{2} \mathrm{Cl}_{2}$ that were dried using standard procedures. The complexes bis[dichlorido $\left(\eta^{6}\right.$-biphenyl) ruthenium(II)] (Mendoza-Ferri et al., 2009), bis[dichlorido ( $\eta^{6}$ - $p$-cymene)ruthenium(II)], $\quad$ bis[dichlorido $\left(\eta^{6}\right.$-benzene) ruthenium(II)], bis[dichlorido $\left(\eta^{6}\right.$-toluene)ruthenium(II)] (Bennett and Smith, 1974; Bennett et al., 1982), dichlorido $\left(\eta^{6}\right.$ p-cymene) (3,5,6-bicyclophosphite-1,2- $O$-isopropylidene- $\alpha$-Dglucofuranose)ruthenium(II) 1a, dichlorido $\left(\eta^{6}\right.$-p-cymene $)(3,5$, 6-bicyclophosphite-1,2-O-cyclohexylidene- $\alpha$-D-glucofuranose) ruthenium(II) $\mathbf{1} \mathbf{b}$ (Berger et al., 2008), and the ligands 3,5,6bicyclophosphite-1,2- $O$-isopropylidene- $\alpha$-D-glucofuranoside I and 3,5,6-bicyclophosphite-1,2-O-cyclohexylidene- $\alpha$-D-glucofuranoside II (Kochetkov et al., 1976) were synthesized using literature procedures. All reactions were carried out in dry solvents under an inert atmosphere. ${ }^{1} \mathrm{H},{ }^{13} \mathrm{C}\left\{{ }^{1} \mathrm{H}\right\}$ and ${ }^{31} \mathrm{P}\left\{{ }^{1} \mathrm{H}\right\}$ NMR spectra were recorded at $25^{\circ} \mathrm{C}$ on a Bruker FT NMR spectrometer Avance III $500 \mathrm{MHz}$ at $500.10\left({ }^{1} \mathrm{H}\right), 125.75\left({ }^{13} \mathrm{C}\left\{{ }^{1} \mathrm{H}\right\}\right)$ and $202.44 \mathrm{MHz}\left({ }^{31} \mathrm{P}\left\{{ }^{1} \mathrm{H}\right\}\right)$ or a Bruker Avance $400 \mathrm{FT}$ NMR spectrometer at $400.13\left({ }^{1} \mathrm{H}\right), 100.63\left({ }^{13} \mathrm{C}\left\{{ }^{1} \mathrm{H}\right\}\right)$ and $161.98 \mathrm{MHz}$ $\left({ }^{31} \mathrm{P}\left\{{ }^{1} \mathrm{H}\right\}\right)$. 2D NMR spectra were collected in a gradientenhanced mode. Melting points were measured on a Büchi B-540 apparatus and are uncorrected. Elemental analysis was performed by the Laboratory for Elemental Analysis, Faculty of Chemistry, University of Vienna, on a Perkin-Elmer $2400 \mathrm{CHN}$ Elemental Analyzer and at the Microanalytical Laboratory of the EPFL. Electrospray ionization mass spectra were recorded on a Bruker esquire $3000 . \mathrm{Na}_{2}$ EDTA.(p.a., Fisher Scientific), $\mathrm{NaOH}$ (Fluka), tris(hydroxymethyl)aminoethane, glacial acetic acid (p.a., Acros), and MilliQ $\mathrm{H}_{2} \mathrm{O}$ (18.2 M $\Omega$, Synergy $185 \mathrm{UV}$ Ultrapure, Millipore, France) were used for the preparation of TAE buffer for gel electrophoresis studies. Loading buffer $(6 \times)$, pBR322 DNA $(0.5 \mu \mathrm{g} / \mu \mathrm{L})$ and GeneRuler ${ }^{\mathrm{TM}} 1 \mathrm{~kb}$ DNA ladder $(0.5 \mu \mathrm{g} / \mu \mathrm{L})$ were obtained from Fermentas.

\section{General procedure for the synthesis of 2-6}

A mixture of bis[dichlorido( $\eta^{6}$-arene)ruthenium(II)] (1 eq.) and the phosphite ligand (2 eq.) in dry $\mathrm{CH}_{2} \mathrm{Cl}_{2}(30 \mathrm{ml})$ was stirred for $3 \mathrm{~h}$ at $40^{\circ} \mathrm{C}$. The solvent was reduced to about $3 \mathrm{~mL}$ on a rotary evaporator, and diethyl ether $(20 \mathrm{~mL})$ was added resulting in orange or brown precipitates which were filtered, washed with diethyl ether $(2 \times 5 \mathrm{~mL})$, and dried under vacuum.

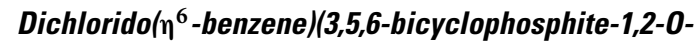 cyclohexylidene- $\alpha$-D-glucofuranose)ruthenium(II) 2}

The title compound was synthesized from 3,5,6-bicyclophosphite-1,2-O-cyclohexylidene- $\alpha$-D-glucofuranose $\quad(58 \mathrm{mg}$, $0.2 \mathrm{mmol})$ and $\left[\left(\eta^{6} \text {-benzene }\right) \operatorname{RuCl}(\mu-\mathrm{Cl})\right]_{2}(50 \mathrm{mg}, 0.1 \mathrm{mmol})$ following the general procedure.

Yield: $104 \mathrm{mg}$ (96\%); m.p. $295-297^{\circ} \mathrm{C}$ (decomp); elemental analysis calcd. for $\mathrm{C}_{18} \mathrm{H}_{23} \mathrm{Cl}_{2} \mathrm{O}_{6} \mathrm{PRu} \cdot 0.5 \mathrm{CH}_{2} \mathrm{Cl}_{2}$ : C 38.25, $\mathrm{H}$ 4.16; found: C 38.21, H 4.19\%; MS $\left(\mathrm{ESI}^{+}\right): m / z: 560.7[\mathrm{M}+\mathrm{Na}]^{+}$; ${ }^{1} \mathrm{H}$ NMR $\left(500.10 \mathrm{MHz}, \mathrm{CDCl}_{3}, 25^{\circ} \mathrm{C}\right): \delta=6.20$ (brs, $1 \mathrm{H} ; \mathrm{H}-$ 1), 5.89 (s, $6 \mathrm{H}$; H-Ar), 5.10-5.13 (m, $1 \mathrm{H}$; H-5), 4.83 (brs, $1 \mathrm{H}$; H-3), 4.75 (brs, $1 \mathrm{H}$; H-2), 4.48-4.50 (m, $1 \mathrm{H}$; H-6), 4.31-4.33 (m, $2 \mathrm{H}$; H-6' $\mathrm{H}-4), 1.57-1.70\left(\mathrm{~m}, 10 \mathrm{H} ; \mathrm{C}_{6} \mathrm{H}_{10}\right) \mathrm{ppm} .{ }^{13} \mathrm{C}\left\{{ }^{1} \mathrm{H}\right\}$ $\operatorname{NMR}\left(125.75 \mathrm{MHz}, \mathrm{CDCl}_{3}, 25^{\circ} \mathrm{C}\right): \delta=113.3\left(\mathrm{C}_{c y c}\right), 105.4(\mathrm{C}-1)$, 91.2 (C-Ar), 83.4 (C-2), 79.5 (C-3), 75.7 (C-4), 75.2 (C-5), 71.5 (C-6), $36.5\left(\mathrm{C}_{6} \mathrm{H}_{10}\right), 35.8\left(\mathrm{C}_{6} \mathrm{H}_{10}\right), 24.8\left(\mathrm{C}_{6} \mathrm{H}_{10}\right), 23.9\left(\mathrm{C}_{6} \mathrm{H}_{10}\right)$, $23.5\left(\mathrm{C}_{6} \mathrm{H}_{10}\right)$ ppm. ${ }^{31} \mathrm{P}\left\{{ }^{1} \mathrm{H}\right\} \mathrm{NMR}\left(202.44 \mathrm{MHz}, \mathrm{CDCl}_{3}, 25^{\circ} \mathrm{C}\right)$ : $\delta=132.7 \mathrm{ppm}$.

\section{Dichlorido/ $\eta^{6}$-toluene)(3,5,6-bicyclophosphite-1,2-0- isopropylidene- $\alpha$-D-glucofuranose)ruthenium(II) 3}

The title compound was synthesized from 3,5,6-bicyclophosphite-1,2-O-isopropylidene- $\alpha$-D-glucofuranose (99 mg, $0.4 \mathrm{mmol})$ and $\left[\left(\eta^{6} \text {-toluene }\right) \mathrm{RuCl}(\mu-\mathrm{Cl})\right]_{2}(106 \mathrm{mg}, 0.2 \mathrm{mmol})$ following the general procedure.

Yield: $201 \mathrm{mg}$ (97\%); m.p. $180-181^{\circ} \mathrm{C}$ (decomp); elemental analysis calcd. for $\mathrm{C}_{16} \mathrm{H}_{21} \mathrm{Cl}_{2} \mathrm{O}_{6} \mathrm{PRu} \cdot 0.25 \mathrm{CH}_{2} \mathrm{Cl}_{2}$ : C 36.58, $\mathrm{H}$ 4.06; found: $\mathrm{C} 36.93, \mathrm{H} 4.22 \%$; $\mathrm{MS}\left(\mathrm{ESI}^{+}\right): \mathrm{m} / z: 534.6$ $[\mathrm{M}+\mathrm{Na}]^{+} ;{ }^{1} \mathrm{H} \mathrm{NMR}\left(500.10 \mathrm{MHz}, \mathrm{CDCl}_{3}, 25^{\circ} \mathrm{C}\right): \delta=6.19$ $\left[\mathrm{d},{ }^{3} \mathrm{~J}(\mathrm{H}, \mathrm{H})=3 \mathrm{~Hz}, 1 \mathrm{H} ; \mathrm{H}-1\right], 5.80-5.82$ (m, $2 \mathrm{H}$; H-Ar), 5.58 (brs, $2 \mathrm{H}$; H-Ar), 5.52 (brs, $1 \mathrm{H}$; H-Ar), 5.09-5.12 (m, $1 \mathrm{H}$; $\mathrm{H}-5), 4.81$ (brs, $1 \mathrm{H} ; \mathrm{H}-3), 4.74\left[\mathrm{~d},{ }^{3} \mathrm{~J}(\mathrm{H}, \mathrm{H})=2 \mathrm{~Hz}, 1 \mathrm{H} ; \mathrm{H}-\right.$ 2], 4.44-4.48 (m, $1 \mathrm{H}$; H-6), 4.31-4.33 (m, $2 \mathrm{H}$; H-6', H-4), $2.34\left(\mathrm{~s}, 3 \mathrm{H} ; \mathrm{Ar}-\mathrm{CH}_{3}\right), 1.52\left[\mathrm{~s}, 3 \mathrm{H} ; \mathrm{C}\left(\mathrm{CH}_{3}\right)_{2}\right], 1.36[\mathrm{~s}, 3 \mathrm{H}$; $\left.\mathrm{C}\left(\mathrm{CH}_{3}\right)_{2}\right] \mathrm{ppm} .{ }^{13} \mathrm{C}\left\{{ }^{1} \mathrm{H}\right\} \mathrm{NMR}\left(125.75 \mathrm{MHz}, \mathrm{CDCl}_{3}, 25^{\circ} \mathrm{C}\right): \delta=$ $113.0\left[\mathrm{C}\left(\mathrm{CH}_{3}\right)_{2}\right], 112.6(\mathrm{C}-\mathrm{Ar}), 105.7(\mathrm{C}-1), 91.0(\mathrm{C}-\mathrm{Ar}), 90.6$ $(\mathrm{C}-\mathrm{Ar}), 83.7\left[{ }^{3} \mathrm{~J}(\mathrm{C}, \mathrm{P})=6 \mathrm{~Hz}, \mathrm{C}-2\right], 82.2(\mathrm{C}-\mathrm{Ar}), 81.8(\mathrm{C}-\mathrm{Ar})$, $79.2\left[{ }^{3} J(\mathrm{C}, \mathrm{P})=8 \mathrm{~Hz}, \mathrm{C}-3\right], 77.2(\mathrm{C}-\mathrm{Ar}), 76.8\left[{ }^{3} \mathrm{~J}(\mathrm{C}, \mathrm{P})=6 \mathrm{~Hz}, \mathrm{C}-\right.$ 4], $74.8\left[{ }^{3} \mathrm{~J}(\mathrm{C}, \mathrm{P})=5 \mathrm{~Hz}, \mathrm{C}-5\right], 69.9\left[{ }^{3} \mathrm{~J}(\mathrm{C}, \mathrm{P})=8 \mathrm{~Hz}, \mathrm{C}-6\right], 26.9$ $\left[\mathrm{C}\left(\mathrm{CH}_{3}\right)_{2}\right], 26.3\left[\mathrm{C}\left(\mathrm{CH}_{3}\right)_{2}\right], 19.2\left(\mathrm{Ar}-\mathrm{CH}_{3}\right) \mathrm{ppm} .{ }^{31} \mathrm{P}\left\{{ }^{1} \mathrm{H}\right\} \mathrm{NMR}$ $\left(202.44 \mathrm{MHz}, \mathrm{CDCl}_{3}, 25^{\circ} \mathrm{C}\right): \delta=134.5 \mathrm{ppm}$.

\section{Dichlorido/ $\eta^{6}$-toluene)(3,5,6-bicyclophosphite-1,2-0- cyclohexylidene- $\alpha-D$-glucofuranose)ruthenium(II) 4}

The title compound was synthesized from 3,5,6-bicyclophosphite-1,2-O-cyclohexylidene- $\alpha$-D-glucofuranose (58 mg, $0.2 \mathrm{mmol})$ and $\left[\left(\eta^{6} \text {-toluene }\right) \mathrm{RuCl}(\mu-\mathrm{Cl})\right]_{2} \quad(53 \mathrm{mg}, 0.1 \mathrm{mmol})$ following the general procedure.

Yield: $107 \mathrm{mg}$ (95\%); m.p. $281-283^{\circ} \mathrm{C}$ (decomp); elemental analysis calcd. for $\mathrm{C}_{19} \mathrm{H}_{25} \mathrm{Cl}_{2} \mathrm{O}_{6} \mathrm{PRu} \cdot 0.15 \mathrm{CH}_{2} \mathrm{Cl}_{2}$ : C 39.37, $\mathrm{H}$ 4.40; found: $\mathrm{C} 39.06, \mathrm{H}$ 4.40\%; $\mathrm{MS}\left(\mathrm{ESI}^{+}\right): \mathrm{m} / z$ : 574.6 $[\mathrm{M}+\mathrm{Na}]^{+} ;{ }^{1} \mathrm{H} \mathrm{NMR}\left(500.10 \mathrm{MHz}, \mathrm{CDCl}_{3}, 25^{\circ} \mathrm{C}\right): \delta=6.18[\mathrm{~d}$, 
${ }^{3} \mathrm{~J}(\mathrm{H}, \mathrm{H})=4 \mathrm{~Hz}, 1 \mathrm{H} ; \mathrm{H}-1$ ] , 5.80-5.82 (m, $2 \mathrm{H}$; H-Ar), 5.58 (brs, $2 \mathrm{H}$; H-Ar), 5.48-5.51 (m, $1 \mathrm{H}$; H-Ar), 5.08-5.12 (m, $1 \mathrm{H}$; H-5), 4.82 (brs, $1 \mathrm{H}$; H-3), 4.73 (brs, $1 \mathrm{H}$; H-2), 4.44-4.48 (m, $1 \mathrm{H}$; H-6), 4.32-4.34 (m, $2 \mathrm{H} ; \mathrm{H}-6$ ', H-4), 2.34 (s, 3 H; Ar-CH ${ }_{3}$ ), 1.67-1.70 $\left(\mathrm{m}, 4 \mathrm{H} ; \mathrm{C}_{6} \mathrm{H}_{10}\right), 1.56-1.58\left(\mathrm{~m}, 6 \mathrm{H} ; \mathrm{C}_{6} \mathrm{H}_{10}\right)$ ppm. ${ }^{13} \mathrm{C}\left\{{ }^{1} \mathrm{H}\right\} \mathrm{NMR}$ $\left(125.75 \mathrm{MHz}, \mathrm{CDCl}_{3}, 25^{\circ} \mathrm{C}\right): \delta=113.7\left(C_{c y c}\right), 112.7$ (C-Ar), 105.3 (C-1), 91.1 (C-Ar), 90.7 (C-Ar), $83.4\left[{ }^{3} J(\mathrm{C}, \mathrm{P})=7 \mathrm{~Hz}, \mathrm{C}-2\right.$ ], 82.3 (C-Ar), 81.6 (C-Ar), $79.4\left[{ }^{3} J(\mathrm{C}, \mathrm{P})=8 \mathrm{~Hz}, \mathrm{C}-3\right], 77.4(\mathrm{C}-$ $\mathrm{Ar}), 76.6\left[{ }^{3} \mathrm{~J}(\mathrm{C}, \mathrm{P})=6 \mathrm{~Hz}, \mathrm{C}-4\right], 74.9\left[{ }^{3} \mathrm{~J}(\mathrm{C}, \mathrm{P})=5 \mathrm{~Hz}, \mathrm{C}-5\right], 69.8$ $\left[{ }^{3} J(\mathrm{C}, \mathrm{P})=8 \mathrm{~Hz}, \mathrm{C}-6\right], 36.9\left(\mathrm{C}_{6} \mathrm{H}_{10}\right), 36.2\left(\mathrm{C}_{6} \mathrm{H}_{10}\right), 24.8\left(\mathrm{C}_{6} \mathrm{H}_{10}\right)$, $24.2\left(\mathrm{C}_{6} \mathrm{H}_{10}\right), 23.5\left(\mathrm{C}_{6} \mathrm{H}_{10}\right), 19.2\left(\mathrm{CH}_{3}\right) \mathrm{ppm} .{ }^{31} \mathrm{P}\left\{{ }^{1} \mathrm{H}\right\} \mathrm{NMR}$ $\left(202.44 \mathrm{MHz}, \mathrm{CDCl}_{3}, 25^{\circ} \mathrm{C}\right): \delta=134.4 \mathrm{ppm}$.

\section{Dichlorido(n ${ }^{6}$-biphenyl)(3,5,6-bicyclophosphite-1,2-0- isopropylidene- $\alpha$-D-glucofuranose)ruthenium(II) 5}

The title compound was synthesized from 3,5,6-bicyclophosphite-1,2-O-isopropylidene- $\alpha$-D-glucofuranose (99 mg, $0.4 \mathrm{mmol})$ and $\left[\left(\eta^{6} \text {-biphenyl }\right) \mathrm{RuCl}(\mu-\mathrm{Cl})\right]_{2}(131 \mathrm{mg}, 0.2 \mathrm{mmol})$ following the general procedure.

Yield: $217 \mathrm{mg}$ (91\%); m.p. $178-179^{\circ} \mathrm{C}$ (decomp); elemental analysis calcd. for $\mathrm{C}_{21} \mathrm{H}_{23} \mathrm{Cl}_{2} \mathrm{O}_{6} \mathrm{PRu} \cdot 0.25 \mathrm{CH}_{2} \mathrm{Cl}_{2}$ : $\mathrm{C} 42.85, \mathrm{H}$ 3.98; found: $\mathrm{C} 42.97, \mathrm{H} 3.88 \%$; $\mathrm{MS}\left(\mathrm{ESI}^{+}\right): \mathrm{m} / z$ : $596.6[\mathrm{M}+$ $\mathrm{Na}]^{+} ;{ }^{1} \mathrm{HNMR}\left(500.10 \mathrm{MHz}, \mathrm{CDCl}_{3}, 25^{\circ} \mathrm{C}\right): \delta=7.69-7.71(\mathrm{~m}$, $2 \mathrm{H}$; H-Ar), 7.48-7.50 (m, 3 H; H-Ar), 6.18-6.22 (m, $3 \mathrm{H}$; HAr), $5.99\left[\mathrm{~d},{ }^{3} J(\mathrm{H}, \mathrm{H})=4 \mathrm{~Hz}, 1 \mathrm{H} ; \mathrm{H}-1\right], 5.88$ (brs, $2 \mathrm{H}$; H-Ar), 5.03-5.07 (m, 1 H; H-5), 4.72 (brs, $1 \mathrm{H} ; \mathrm{H}-3), 4.38-4.44$ (m, $2 \mathrm{H}$; H-6', H-2), 4.26 (brs, $1 \mathrm{H}$; H-4), 4.19 (brs, $1 \mathrm{H}$; H-6), 1.50 [s, $\left.3 \mathrm{H} ; \mathrm{C}\left(\mathrm{CH}_{3}\right)_{2}\right], 1.33\left[\mathrm{~s}, 3 \mathrm{H} ; \mathrm{C}\left(\mathrm{CH}_{3}\right)_{2}\right] \mathrm{ppm} .{ }^{13} \mathrm{C}\left\{{ }^{1} \mathrm{H}\right\} \mathrm{NMR}$ $\left(125.75 \mathrm{MHz}, \mathrm{CDCl}_{3}, 25^{\circ} \mathrm{C}\right): \delta=133.7$ (C-Ar), 130.1 (C-Ar), 129.0 (C-Ar), 128.8 (C-Ar), 128.7 (C-Ar), 127.3 (C-Ar), 112.5 [C $\left.\left(\mathrm{CH}_{3}\right)_{2}\right], 108.3$ (C-Ar), 105.7 (C-1), 91.2 (C-Ar), 90.8 (C-Ar), 89.9 (C-Ar), 88.9 (C-Ar), 88.2 (C-Ar), $83.5\left[{ }^{3} J(\mathrm{C}, \mathrm{P})=5 \mathrm{~Hz}\right.$, $\mathrm{C}-2], 79.1\left[{ }^{3} \mathrm{~J}(\mathrm{C}, \mathrm{P})=8 \mathrm{~Hz}, \mathrm{C}-3\right], 76.8(\mathrm{C}-4), 74.9\left[{ }^{3} \mathrm{~J}(\mathrm{C}, \mathrm{P})=\right.$ $5 \mathrm{~Hz}, \mathrm{C}-5], 69.6(\mathrm{C}-6), 26.9\left[\mathrm{C}\left(\mathrm{CH}_{3}\right)_{2}\right], 26.3\left[\mathrm{C}\left(\mathrm{CH}_{3}\right)_{2}\right] \mathrm{ppm}$. ${ }^{31} \mathrm{P}\left\{{ }^{1} \mathrm{H}\right\} \mathrm{NMR}\left(202.44 \mathrm{MHz}, \mathrm{CDCl}_{3}, 25^{\circ} \mathrm{C}\right): \delta=132.3 \mathrm{ppm}$.

\section{Dichlorido(n ${ }^{6}$-biphenyl)(3,5,6-bicyclophosphite-1,2-0- cyclohexylidene- $\alpha$-D-glucofuranose)ruthenium(II) 6}

The title compound was synthesized from 3,5,6-bicyclophosphite-1,2- $O$-cyclohexylidene- $\alpha$-D-glucofuranose $\quad(58 \mathrm{mg}$, $0.2 \mathrm{mmol})$ and $\left[\left(\eta^{6} \text {-biphenyl }\right) \operatorname{RuCl}(\mu-\mathrm{Cl})\right]_{2}(65 \mathrm{mg}, 0.1 \mathrm{mmol})$ following the general procedure.

Yield: $119 \mathrm{mg}$ (93\%); m.p. $170-172^{\circ} \mathrm{C}$ (decomp); elemental analysis calcd. for $\mathrm{C}_{24} \mathrm{H}_{27} \mathrm{Cl}_{2} \mathrm{O}_{6} \mathrm{PRu} \cdot 0.3 \mathrm{CH}_{2} \mathrm{Cl}_{2}$ : C 45.61, H 4.35; found: C 45.27, H 4.38\%; MS (ESI $\left.{ }^{+}\right): m / z: 636.7[\mathrm{M}+\mathrm{Na}]^{+}$; ${ }^{1} \mathrm{H}$ NMR $\left(500.10 \mathrm{MHz} \mathrm{CDCl}_{3}, 25^{\circ} \mathrm{C}\right): \delta=7.62-7.69(\mathrm{~m}, 2 \mathrm{H}$; H-Ar), 7.46-7.49 (m, 3 H; H-Ar), 6.17-6.20 (m, 3 H; H-Ar), 5.98 $\left[\mathrm{d},{ }^{3} \mathrm{~J}(\mathrm{H}, \mathrm{H})=4 \mathrm{~Hz}, 1 \mathrm{H} ; \mathrm{H}-1\right.$ ], 5.87 (brs, $2 \mathrm{H} ; \mathrm{H}-\mathrm{Ar}$ ), 5.03-5.05 (m, $1 \mathrm{H} ; \mathrm{H}-5), 4.73$ (brs, $1 \mathrm{H}$; H-3), 4.43-4.46 (m, 2 H; H-6', H-2), 4.26 (brs, $1 \mathrm{H} ; \mathrm{H}-4), 4.18$ (brs, $1 \mathrm{H}$; H-6), 1.65-1.67 (m, $\left.4 \mathrm{H} ; \mathrm{C}_{6} \mathrm{H}_{10}\right), 1.54-1.58\left(\mathrm{~m}, 6 \mathrm{H} ; \mathrm{C}_{6} \mathrm{H}_{10}\right) \mathrm{ppm} .{ }^{13} \mathrm{C}\left\{{ }^{1} \mathrm{H}\right\} \mathrm{NMR}$ $\left(125.75 \mathrm{MHz}, \mathrm{CDCl}_{3}, 25^{\circ} \mathrm{C}\right): \delta=133.6$ (C-Ar), 130.1 (C-Ar), 129.0 (C-Ar), 128.8 (C-Ar), 128.6 (C-Ar), 127.2 (C-Ar), 113.2 $\left(C_{c y c}\right), 108.5(\mathrm{C}-\mathrm{Ar}), 105.4$ (C-1), 91.3 (C-Ar), 90.6 (C-Ar), 90.0 (C-Ar), 89.0 (C-Ar), 88.3 (C-Ar), $83.2\left[{ }^{3} J(\mathrm{C}, \mathrm{P})=6 \mathrm{~Hz}, \mathrm{C}-2\right]$, $79.3\left[{ }^{3} J(\mathrm{C}, \mathrm{P})=8 \mathrm{~Hz}, \mathrm{C}-3\right], 76.6(\mathrm{C}-4), 75.0\left[{ }^{3} \mathrm{~J}(\mathrm{C}, \mathrm{P})=5 \mathrm{~Hz}, \mathrm{C}-\right.$ 5], $70.0(\mathrm{C}-6), 36.5\left(\mathrm{C}_{6} \mathrm{H}_{10}\right), 35.8\left(\mathrm{C}_{6} \mathrm{H}_{10}\right), 24.8\left(\mathrm{C}_{6} \mathrm{H}_{10}\right), 23.9$
$\left(\mathrm{C}_{6} \mathrm{H}_{10}\right), 23.5\left(\mathrm{C}_{6} \mathrm{H}_{10}\right)$ ppm. ${ }^{31} \mathrm{P}\left\{{ }^{1} \mathrm{H}\right\} \mathrm{NMR}\left(202.44 \mathrm{MHz}, \mathrm{CDCl}_{3}\right.$, $\left.25^{\circ} \mathrm{C}\right): \delta=132.4 \mathrm{ppm}$.

\section{Dichlorido/ ${ }^{6}$-phenoxyethanol)(3,5,6-bicyclophosphite-1,2-0- isopropylidene- $\alpha-D$-glucofuranoside)ruthenium(II) 7}

3,5,6-Bicyclophosphite-1,2-O-isopropylidene- $\alpha$-D-glucofuranoside $(200 \mathrm{mg}, 0.8 \mathrm{mmol})$ was added to a solution of $\left\{\left(\eta^{6}\right.\right.$-phenoxyethanol $) \mathrm{RuCl}(\mu-\mathrm{Cl})\}_{2}(250 \mathrm{mg}, 0.4 \mathrm{mmol})$ in $\mathrm{CH}_{2} \mathrm{Cl}_{2}(30 \mathrm{~mL})$. The reaction mixture was stirred for $12 \mathrm{~h}$ at room temperature. The insoluble residue was removed by filtration and diethyl ether was added to a red solution in order to precipitate the crude product. The pure product was obtained by purification on a silica gel column with $\mathrm{CH}_{2} \mathrm{Cl}_{2}$ : $\mathrm{MeOH}(20: 1)$ as eluent. Yield: $268 \mathrm{mg}$ (60\%); m.p. $120-121^{\circ} \mathrm{C}$ (decomp); elemental analysis calcd. for $\mathrm{C}_{17} \mathrm{H}_{23} \mathrm{O}_{8} \mathrm{RuPCl}_{2}$ : C 36.57, $\mathrm{H}$ 4.15; Found: C 36.96, H 4.35\%; MS $\left(\mathrm{ESI}^{+}\right) \mathrm{m} / z$ : $522[\mathrm{M}-\mathrm{Cl}]^{+} ;{ }^{1} \mathrm{H}$ NMR $\left(400.13 \mathrm{MHz}, \mathrm{D}_{2} \mathrm{O}, 25^{\circ} \mathrm{C}\right): \delta=6.25\left[\mathrm{~d},{ }^{3} \mathrm{~J}(\mathrm{H}, \mathrm{H})=3.5 \mathrm{~Hz}, 1 \mathrm{H}\right.$; $\mathrm{H}-1$ ], 6.20 (m, 2 H; H-Ar), 5.65 (m, $2 \mathrm{H}$; H-Ar), 5.30 (m, 1 H; H-Ar), 5.24 (m, $1 \mathrm{H}$; H-5), 4.98 (m, $1 \mathrm{H} ; \mathrm{H}-3), 4.89$ [d, ${ }^{3} J(\mathrm{H}, \mathrm{H})$ $=3.5 \mathrm{~Hz}, 1 \mathrm{H} ; \mathrm{H}-2], 4.86\left[\mathrm{dd},{ }^{2} J(\mathrm{H}, \mathrm{H})=11.8 \mathrm{~Hz},{ }^{3} J(\mathrm{H}, \mathrm{P})=\right.$ $9.9 \mathrm{~Hz}, 1 \mathrm{H} ; \mathrm{H}-6], 4.57$ (m, $1 \mathrm{H} ; \mathrm{H}-4), 4.32$ (m, $\left.1 \mathrm{H} ; \mathrm{H}-6^{\prime}\right), 4.3$ $\left[\mathrm{t},{ }^{3} \mathrm{~J}(\mathrm{H}, \mathrm{H})=4.3 \mathrm{~Hz}, 2 \mathrm{H}\right.$; O- $\left.\mathrm{CH}_{2}-\mathrm{CH}_{2}-\mathrm{OH}\right], 3.94\left[\mathrm{t},{ }^{3} \mathrm{~J}(\mathrm{H}, \mathrm{H})\right.$ $\left.=4.3 \mathrm{~Hz}, 2 \mathrm{H} ; \mathrm{O}-\mathrm{CH}_{2}-\mathrm{CH}_{2}-\mathrm{OH}\right], 1.51\left(\mathrm{~s}, 3 \mathrm{H} ; \mathrm{CH}_{3}\right), 1.37(\mathrm{~s}$, $\left.3 \mathrm{H} ; \mathrm{CH}_{3}\right)$ ppm. ${ }^{13} \mathrm{C}\left\{{ }^{1} \mathrm{H}\right\} \mathrm{NMR} \quad\left(100.63 \mathrm{MHz}, \mathrm{CDCl}_{3}, 25^{\circ} \mathrm{C}\right)$ : $\delta=145.3(\mathrm{C}-\mathrm{Ar}), 112.6\left[\mathrm{C}\left(\mathrm{CH}_{3}\right)_{2}\right], 105.8(\mathrm{C}-1), 94.3(\mathrm{C}-\mathrm{Ar})$, $93.7(\mathrm{C}-\mathrm{Ar}), 83.6\left[{ }^{3} \mathrm{~J}(\mathrm{C}, \mathrm{P})=6.1 \mathrm{~Hz} ; \mathrm{C}-2\right], 79.0\left[{ }^{2} \mathrm{~J}(\mathrm{C}, \mathrm{P})=\right.$ $8.0 \mathrm{~Hz}$; C-3], 77.2 (C-4), 74.7 (C-Ar or C-5), 73.8 (C-Ar or C-5), $72.8\left(\mathrm{C}-\mathrm{Ar}, \mathrm{O}-\mathrm{CH}_{2}\right), 69.0(\mathrm{C}-6), 60.8\left(\mathrm{CH}_{2}-\mathrm{OH}\right), 26.9\left(\mathrm{CH}_{3}\right)$, $26.2\left(\mathrm{CH}_{3}\right)$ ppm. ${ }^{31} \mathrm{P}\left\{{ }^{1} \mathrm{H}\right\} \mathrm{NMR}\left(161.98 \mathrm{MHz}, \mathrm{CDCl}_{3}, 25^{\circ} \mathrm{C}\right)$ : $\delta=137.1 \mathrm{ppm}$.

\section{Dichlorido(n ${ }^{6}$-phenoxyethanol)(3,5,6-bicyclophosphite-1,2-0- cyclohexylidene- $\alpha$-D-glucofuranoside)ruthenium(II) 8}

3,5,6-Bicyclophosphite-1,2-O-cyclohexylidene- $\alpha$-D-glucofuranoside $(230 \mathrm{mg}, 0.8 \mathrm{mmol})$ was added to a solution of $\left\{\left(\eta^{6}\right.\right.$-phenoxyethanol) $\mathrm{RuCl}(\mu-\mathrm{Cl})\}_{2}(250 \mathrm{mg}, 0.4 \mathrm{mmol})$ in $\mathrm{CH}_{2} \mathrm{Cl}_{2}(30 \mathrm{~mL})$. The reaction mixture was stirred for $12 \mathrm{~h}$ at room temperature. The insoluble residue was removed by filtration and diethyl ether was added to a red solution in order to precipitate the crude product. The pure product was obtained by purification on a silica gel column with $\mathrm{CH}_{2} \mathrm{Cl}_{2}$ : $\mathrm{MeOH}(20: 1)$ as eluent. Yield: $350 \mathrm{mg}(73 \%)$; m.p. $90-91^{\circ} \mathrm{C}$ (decomp); elemental analysis calcd. for $\mathrm{C}_{20} \mathrm{H}_{27} \mathrm{O}_{8} \mathrm{RuPCl}_{2}$ : C 40.14, $\mathrm{H} 4.55$; Found: $\mathrm{C} 40.41, \mathrm{H} 4.73 \%$; MS $\left(\mathrm{ESI}^{+}\right) \mathrm{m} / z: 563[\mathrm{M} \mathrm{-} \mathrm{Cl}]^{+} ;{ }^{1} \mathrm{H}$ NMR $\left(400.13 \mathrm{MHz}, \mathrm{CD}_{2} \mathrm{Cl}_{2}\right.$, $\left.25^{\circ} \mathrm{C}\right): \delta=6.19\left[\mathrm{~d},{ }^{3} \mathrm{~J}(\mathrm{H}, \mathrm{H})=4 \mathrm{~Hz}, 1 \mathrm{H} ; \mathrm{H}-1\right], 5.98(\mathrm{~m}, 2 \mathrm{H} ; \mathrm{H}-$ Ar), 5.53 (m, 2 H; H-Ar), 5.13 (m, $1 \mathrm{H}$; H-Ar), 5.10 (m, $1 \mathrm{H}$; H-5), $4.82(\mathrm{~m}, 1 \mathrm{H} ; \mathrm{H}-3), 4.73\left[\mathrm{~d},{ }^{3} \mathrm{~J}(\mathrm{H}, \mathrm{H})=4 \mathrm{~Hz}, 1 \mathrm{H} ; \mathrm{H}-2\right], 4.50$ [dd, $\left.{ }^{2} \mathrm{~J}(\mathrm{H}, \mathrm{H})=12 \mathrm{~Hz},{ }^{3} \mathrm{~J}(\mathrm{H}, \mathrm{P})=9 \mathrm{~Hz}, 1 \mathrm{H} ; \mathrm{H}-6\right], 4.40\left[\mathrm{t},{ }^{3} \mathrm{~J}(\mathrm{H}, \mathrm{H})=\right.$ $4 \mathrm{~Hz}, 2 \mathrm{H}$; O- $\left.\mathrm{CH}_{2}-\mathrm{CH}_{2}-\mathrm{OH}\right], 4.33(\mathrm{~m}, 1 \mathrm{H} ; \mathrm{H}-4), 4.28(\mathrm{~m}, 1 \mathrm{H}$; $\left.\mathrm{H}-6^{\prime}\right), 3.97\left[\mathrm{t},{ }^{3} \mathrm{~J}(\mathrm{H}, \mathrm{H})=4 \mathrm{~Hz}, 2 \mathrm{H} ; \mathrm{O}-\mathrm{CH}_{2}-\mathrm{CH}_{2}-\mathrm{OH}\right], 3.37$ (brs, $1 \mathrm{H} ; \mathrm{OH}), 1.70-1.24\left(\mathrm{~m}, 10 \mathrm{H} ; \mathrm{CH}_{2}\right) \mathrm{ppm} .{ }^{\overline{13}} \mathrm{C}\left\{{ }^{1} \mathrm{H}\right\} \mathrm{NMR}$ $\left(100.63 \mathrm{MHz}, \mathrm{CD}_{2} \mathrm{Cl}_{2}, 25^{\circ} \mathrm{C}\right): \delta=145.0(\mathrm{C}-\mathrm{Ar}), 113.2\left(\mathrm{C}_{6} \mathrm{H}_{10}\right)$, 105.4 (C-1), 94.0 (C-Ar), 93.6 (C-Ar), $83.3\left[{ }^{3} \mathrm{~J}(\mathrm{C}, \mathrm{P})=6.0 \mathrm{~Hz}\right.$; $\mathrm{C}-2], 79.2\left[{ }^{2} J(\mathrm{C}, \mathrm{P})=8.3 \mathrm{~Hz} ; \mathrm{C}-3\right], 76.8\left[{ }^{3} \mathrm{~J}(\mathrm{C}, \mathrm{P})=4.9 \mathrm{~Hz}\right.$; $\mathrm{C}-4], 74.6\left[{ }^{2} J(\mathrm{C}, \mathrm{P})=5.7 \mathrm{~Hz}\right.$; C-5], 73.7 (C-Ar), 72.9 (C-Ar), $72.7\left(\mathrm{O}-\mathrm{CH}_{2}\right), 69.2\left[{ }^{2} \mathrm{~J}(\mathrm{C}, \mathrm{P})=9.2 \mathrm{~Hz} ; \mathrm{C}-6\right], 60.6\left(\mathrm{CH}_{2}-\mathrm{OH}\right)$, $36.4\left(\mathrm{C}_{6} \mathrm{H}_{10}\right), 35.7\left(\mathrm{C}_{6} \mathrm{H}_{10}\right), 24.8\left(\mathrm{C}_{6} \mathrm{H}_{10}\right), 23.9\left(\mathrm{C}_{6} \mathrm{H}_{10}\right), 23.6$ 
$\left(\mathrm{C}_{6} \mathrm{H}_{10}\right)$ ppm. ${ }^{31} \mathrm{P}\left\{{ }^{1} \mathrm{H}\right\}$ NMR $\left(161.98 \mathrm{MHz}, \mathrm{CD}_{2} \mathrm{Cl}_{2}, 25^{\circ} \mathrm{C}\right): \delta=$ $137.1 \mathrm{ppm}$.

\section{Hydrolysis and reactivity with 9-ethylguanine (9-EtG)}

For hydrolysis studies, the compounds were dissolved in $\mathrm{D}_{2} \mathrm{O}$ and the samples were analyzed by ${ }^{1} \mathrm{H}$ and ${ }^{31} \mathrm{P}\left\{{ }^{1} \mathrm{H}\right\}$ NMR spectroscopy after 1, 24, 48 and $96 \mathrm{~h}$. For 9-ethylguanine binding experiments, the complexes were mixed at molar ratios of $1: 1$ and 1: 2 (complex: 9-EtG) in $\mathrm{D}_{2} \mathrm{O}$ and reaction progress was monitored by ${ }^{1} \mathrm{H}$ and ${ }^{31} \mathrm{P}\left\{{ }^{1} \mathrm{H}\right\}$ NMR spectroscopy after 1,24 and $96 \mathrm{~h}$, while samples were kept at room temperature during this time period.

\section{DNA interaction studies}

The structural modification of DNA by $\mathbf{2}, \mathbf{4}$, and $\mathbf{6}$ was tested by agarose gel electrophoresis with the plasmid pBR322. TAE (1x) buffer was employed as incubation medium. Stock solutions of $1 \mathrm{mM}$ of complex 2, $\mathbf{4}$, and $\mathbf{6}$ were prepared in TAE (1x) buffer, diluted with TAE $(1 \mathrm{x})$ buffer and stored at $-20^{\circ} \mathrm{C}$. The plasmid pBR322 was diluted with TAE (1x) buffer as well. Incubation mixtures were prepared to yield $r_{\mathrm{b}}$-values corresponding to $0.01,0.05$, $0.10,0.50,1.00$ and 5.00 .

The agarose gels consisted of $1 \%$ agarose in TAE $(1 \times)$ buffer, and the incubation mixtures were subject to $35 \mathrm{~min}$ running time at $100 \mathrm{~V}$ and $70 \mathrm{~mA}$ in a PerfectBlue ${ }^{\mathrm{TM}}$ Mini S (PEQLAB) GE chamber. The DNA bands were stained with ethidium bromide $(1 \mu \mathrm{l} / \mathrm{mL})$ and were processed and analyzed with the gel documentation system GenoView UV-source and GenoSoft Version 3.08 C (VWR).

\section{Cathepsin B inhibition assay}

Crude bovine spleen cathepsin B (cat B) was purchased from Sigma (C6286) and used without further purification. The colorimetric cat B assay was performed in $100 \mathrm{mM}$ sodium phosphate, $1 \mathrm{mM}$ EDTA, $0.025 \%$ polyoxyethylene (23) lauryl ether (BRIJ), pH 6.0, using Na-CBZ-L-lysine $p$-nitrophenyl ester $(\mathrm{CBZ}=\mathrm{N}$ carbobenzoxy) as substrate. For the enzyme to be catalytically functional, the active site cysteine needs to be in a reduced form which was accomplished before dilution with an excess of dithiothreitol (DTT) for $1 \mathrm{~h}$ at $30^{\circ} \mathrm{C}$. $\mathrm{IC}_{50}$ determinations were performed in triplicate using a fixed enzyme concentration of $500 \mathrm{nM}$ and a fixed substrate concentration of $200 \mu \mathrm{M}$. Inhibitor concentrations ranged from 0.3 to $200 \mu \mathrm{M}$.

The enzyme and inhibitor were co-incubated at $30^{\circ} \mathrm{C}$ over a period of $24 \mathrm{~h}$ prior to the addition of substrate. Activity was measured over $3 \mathrm{~min}$ at $326 \mathrm{~nm}$. Colorimetric readings were performed on a Lambda 20 Bio spectrophotometer (Perkin-Elmer).

\section{Cytotoxicity studies}

Cell lines and culture conditions. $\mathrm{CH} 1$ cells originate from an ascites sample of a patient with a papillary cystadenocarcinoma of the ovary and were a gift from Lloyd R. Kelland, CRC Centre for Cancer Therapeutics, Institute of Cancer Research, Sutton, UK. SW480 (adenocarcinoma of the colon, human), and A549 (non-small cell lung cancer, human) cells were provided by Brigitte Marian (Institute of Cancer Research, Department of Medicine I, Medical University of Vienna, Austria). All cell culture media and reagents were obtained from Sigma-Aldrich Austria.
Cells were grown in $75 \mathrm{~cm}^{2}$ culture flasks (Iwaki) as adherent monolayer cultures in Eagle's Minimal Essential Medium (MEM) supplemented with $10 \%$ heat-inactivated fetal calf serum, $1 \% \mathrm{v} / \mathrm{v}$ non-essential amino acids (from $100 \times$ ready-to-use stock), $1 \mathrm{~mm}$ sodium pyruvate and $4 \mathrm{~mm}$ L-glutamine (complete medium). Cultures were maintained at $37^{\circ} \mathrm{C}$ in a humidified atmosphere containing $95 \%$ air and $5 \% \mathrm{CO}_{2}$.

MTT assay conditions. Cytotoxicity was determined using the colorimetric MTT (3-(4,5-dimethyl-2-thiazolyl)-2,5-diphenyl$2 \mathrm{H}$-tetrazolium bromide, Fluka) assay. $\mathrm{CH} 1, \mathrm{SW} 480$ and A549 cells were harvested from the culture flasks by trypsinization, and $100 \mu \mathrm{L}$ aliquots were seeded into 96-well microculture plates (Iwaki/Asahi Technoglass, Gyouda, Japan) in complete medium. Densities of $1.5 \times 10^{3}(\mathrm{CH} 1), 2.5 \times 10^{3}(\mathrm{SW} 480)$ and $4 \times 10^{3}$ (A549) cells per well were chosen in order to ensure exponential growth of untreated controls throughout the experiment. Cells were allowed to settle for $24 \mathrm{~h}$. Then, the test compounds were dissolved and serially diluted in complete medium, and $100 \mu \mathrm{L}$ aliquots were added to the microcultures. Cells were exposed to the test compounds for $96 \mathrm{~h}$. After exposure, all media were replaced with 1:6 MTT/RPMI mixture $(100 \mu \mathrm{L}$ per well $)$ containing MTT solution in phosphate-buffered saline $(5 \mathrm{mg} / \mathrm{ml})$ and MTT/RPMI1640 culture medium (supplemented with 10\% heat-inactivated fetal calf serum and $4 \mathrm{mM}$ L-glutamine). After incubation for $4 \mathrm{~h}$, the supernatants were removed, and the formazan crystals formed in viable cells were dissolved in $150 \mu \mathrm{L}$ DMSO per well. Optical densities were measured at $550 \mathrm{~nm}$ with a microplate reader (Tecan Spectra Classic), using a reference wavelength of $690 \mathrm{~nm}$ to correct the unspecific absorption. The quantity of viable cells was expressed in terms of T/C values by comparison to untreated control, and 50\% inhibitory concentrations $\left(\mathrm{IC}_{50}\right)$ were calculated from concentration-effect curves by interpolation. Evaluation is based on means from at least three independent experiments, each comprising three replicates per concentration level.

\section{Determination of cellular accumulation of the complexes}

The cellular accumulation study was conducted following a previously published protocol (Egger et al., 2009). SW480 cells were seeded in 6-well plates (Iwaki/Asahi Technoglass, Gyouda, Japan) in $2.5 \mathrm{~mL}$ complete medium (MEM) per well in densities of about $3 \times 10^{5}$ cells per well. Cell microcultures were incubated in a moist atmosphere at $37^{\circ} \mathrm{C}$ for $24 \mathrm{~h}$ prior to exposure to the test compounds. The cell number was determined using trypan blue staining in parallel microcultures during the $2 \mathrm{~h}$ exposure period. After exposure the medium was removed, cells were washed with PBS and consecutively lyzed with $0.5 \mathrm{~mL}$ sub-boiled $\mathrm{HNO}_{3}$ (conc.) per well for $1 \mathrm{~h}$. The Ru concentration was quantified by ICP-MS in presence of $0.5 \mu \mathrm{M}$ indium used as internal standard. Results are based on three independent experiments, each consisting of three replicates.

\section{RESULTS AND DISCUSSION}

In order to further improve the specificity and efficacy of sugarbased RAPTA analogues, we have prepared further compounds carrying benzene, toluene, biphenyl and phenoxyethanol as the 
$\pi$-bound arene ligands, in order to explore the influence of the arene ligand on the antitumor activity of the compounds as well as on their modes of action. The organometallic $\mathrm{Ru}^{\mathrm{II}}$-chlorido complexes 2-8 were synthesized by reacting 3,5,6-bicyclophosphite-1,2-O-isopropylidene- $\alpha$-D-glucofuranoside I or 3,5,6bicyclophosphite-1,2-O-cyclohexylidene- $\alpha$-D-glucofuranoside II with the respective bis[dichlorido $\left(\eta^{6}\right.$-arene) ruthenium(II)] precursor in $\mathrm{CH}_{2} \mathrm{Cl}_{2}$ (Figure 2) (Berger et al., 2008; Hanif et al., 2010a). All the complexes were obtained in very good yield and were characterized by $1 \mathrm{D}$ and 2D NMR spectroscopy, ESI-MS, and elemental analysis. In the ${ }^{1} \mathrm{H}$ NMR spectra, protons of the coordinated arene ligands give rise to signals that appear in the range $5-6 \mathrm{ppm}$. Complexes 5 and $\mathbf{6}$, which contain a $\eta^{6}$-biphenyl ligand, exhibit additional resonances due to the aromatic protons from the second phenyl ring at $c a$. $7-8 \mathrm{ppm}$. The benzene ligand in 2 gives a singlet resonance at $6.20 \mathrm{ppm}$. The coordination of the P-donor sugar-based ligands to the metal center results in a dramatic change in the ${ }^{31} \mathrm{P}\left\{{ }^{1} \mathrm{H}\right\}$ NMR singlet resonance from $c a$. 117 to $135 \mathrm{ppm}$, which is similar to that of analogous compounds (Berger et al., 2008). Moreover, the presence of the NMR active phosphorus nucleus induces splitting of some of the carbon signals of coordinated arene moieties due to P-C coupling (Berger et al., 2008). ESI-MS further confirms the structures with peaks of high relative intensity that may be assigned to $[\mathrm{M}+\mathrm{Na}]^{+}$or $[\mathrm{M}-\mathrm{Cl}]^{+}$ions for all compounds.

The hydrolysis of $\mathbf{2}, \mathbf{3}, \mathbf{7}$, and $\mathbf{8}$ was studied by ${ }^{31} \mathrm{P}\left\{{ }^{1} \mathrm{H}\right\} \mathrm{NMR}$ spectroscopy and parallels earlier findings for la (Berger et al., 2008). Dissolution of $\mathbf{2}$ and $\mathbf{3}$ in water results after 1 h-incubation in a single peak at about $136 \mathrm{ppm}$, which is assignable to the parent compound and indicates stability within this time period. Within $24 \mathrm{~h}$, two additional peaks of equal relative intensity at 137.4 and $136.8 \mathrm{ppm}$ appear due to formation of diastereomers by exchange of a single chlorido ligand with an aqua molecule. This was accompanied by the cleavage of a $\mathrm{P}-\mathrm{O}$ bond as indicated by signals of equal relative intensity at 95.7 and $94.5 \mathrm{ppm}$, while an additional signal at $94.7 \mathrm{ppm}$ is assigned to a compound in which $\mathrm{P}-\mathrm{O}$ bond cleavage occurred. The ${ }^{31} \mathrm{P}\left\{{ }^{1} \mathrm{H}\right\}$ NMR spectrum recorded after $48 \mathrm{~h}$ contains two additional signals at 123.8

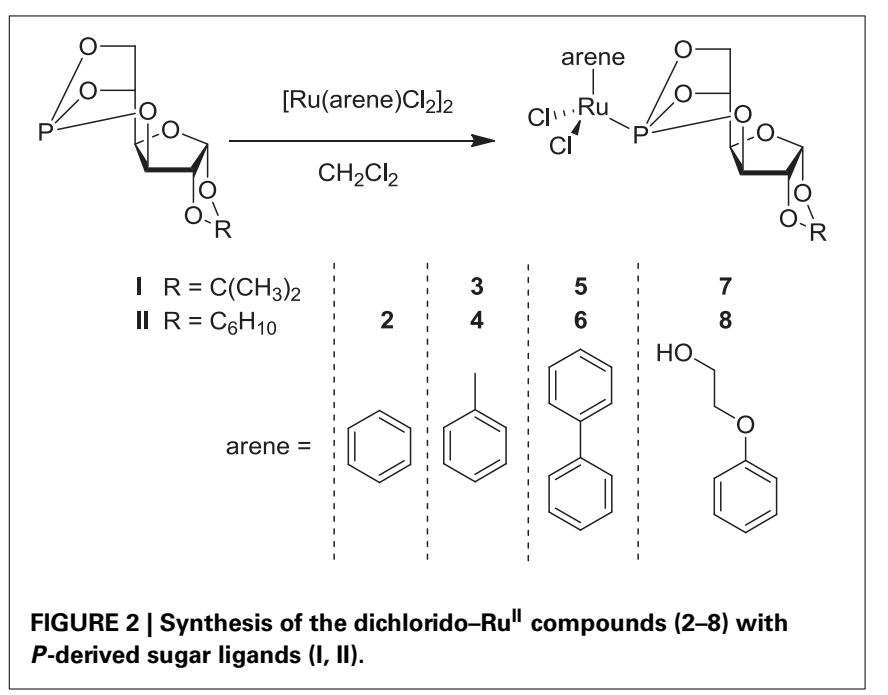

and $122.4 \mathrm{ppm}$, probably due to formation of dimeric species. The sequence of formation of hydrolytic species is similar to that observed for related ruthenium(II) compounds (Scolaro et al., 2005; Berger et al., 2008; Scolaro et al., 2008; Hanif et al., 2010a; Nazarov et al., 2012). Extending the reaction time to $96 \mathrm{~h}$ did not result in the formation of additional species, and it seems that an equilibrium has been reached with $60-70 \%$ of the compound remaining in its original form. A similar process was observed for $\mathbf{7}$ and 8, demonstrating that the addition of a hydroxyl functionality to the arene ligand does not alter the aquation profile.

\section{BIOLOGICAL EVALUATION}

The cancer-inhibiting potential of $\mathbf{2 - 6}$ and $\mathbf{8}$ was determined in human SW480 colon adenocarcinoma, $\mathrm{CH} 1$ ovarian cancer and A549 non-small cell lung cancer cells by using the MTT assay. The obtained results are compared to those of analogous $\mathrm{Ru}(\mathrm{II})$ compounds in Table 1, and the concentration-effect curves of $\mathbf{1 b}, \mathbf{2}, \mathbf{4}, \mathbf{6}$, and 8 in $\mathrm{CH} 1$ cells, which are usually most sensitive to the treatment with metal compounds, are shown in Figure 3.

Table 1 | Cellular accumulation in SW480 colon cancer cells and in vitro anticancer activity (mean $\mathrm{IC}_{50}$ values \pm standard deviations) of 1-6 and 8 in human ovarian cancer ( $\mathrm{CH} 1)$, colon adenocarcinoma (SW480), and non-small cell lung cancer (A549) cells (exposure time $96 \mathrm{~h})$.

\begin{tabular}{lllll}
\hline Compound & $\begin{array}{l}\text { Cellular uptake/ } \\
\text { Ru [fg/cell] }\end{array}$ & \multicolumn{3}{c}{ IC $_{\mathbf{5 0}}$ values/ $\boldsymbol{\mu M}$} \\
\cline { 3 - 5 } & & $\mathbf{C H 1}$ & $\mathbf{s W 4 8 0}$ & $\mathbf{A 5 4 9}$ \\
\hline $\mathbf{1 a}$ & $10 \pm 2$ & $60 \pm 14^{\mathrm{a}}$ & $361 \pm 122^{\mathrm{a}}$ & $498 \pm 17^{\mathrm{a}}$ \\
$\mathbf{1 b}$ & $20 \pm 2$ & $29 \pm 4^{\mathrm{a}}$ & $150 \pm 19^{\mathrm{a}}$ & $223 \pm 14^{\mathrm{a}}$ \\
$\mathbf{2}$ & $29 \pm 6$ & $118 \pm 36$ & $129 \pm 13$ & $417 \pm 68$ \\
$\mathbf{3}$ & n.d. & $164 \pm 47$ & $276 \pm 6$ & $427 \pm 163$ \\
$\mathbf{4}$ & $18 \pm 3$ & $92 \pm 22$ & $99 \pm 13$ & $486 \pm 55$ \\
$\mathbf{5}$ & $74 \pm 9$ & $29 \pm 3$ & $26 \pm 5$ & $>160$ \\
$\mathbf{6}$ & $224 \pm 33$ & $3.9 \pm 0.3$ & $5.3 \pm 0.9$ & $56 \pm 9$ \\
$\mathbf{8}$ & $4 \pm 1$ & $189 \pm 3$ & $260 \pm 52$ & $314 \pm 32$ \\
\hline RAPTA-C & n.d. & $65 \pm 15$ & $171 \pm 59$ & $>515$ \\
\hline
\end{tabular}

${ }^{a}$ From Berger et al. (2008); n.d., not determined.

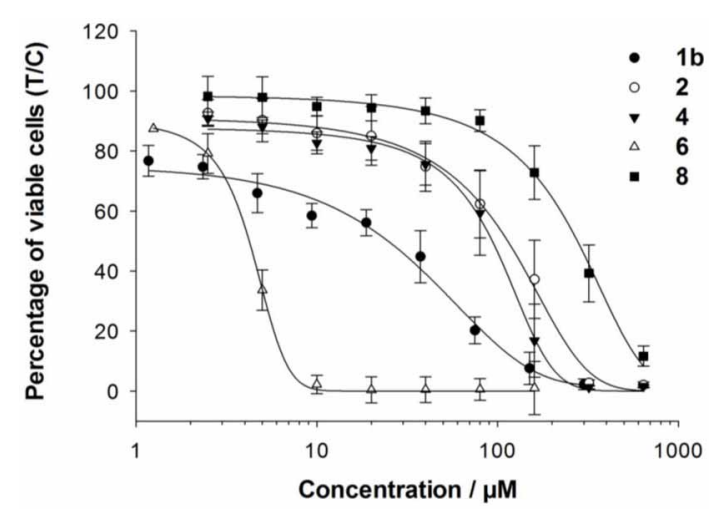

FIGURE 3 | Concentration-effect curves of $1 \mathrm{~b}, 2,4,6$, and 8 in $\mathrm{CH} 1$ cells. 
Variation in the arene ligand of the $\mathrm{Ru}$ complexes has a strong influence on antiproliferative activity, which is improved with increasing the lipophilic character of the arene and carbohydrate ligands in line with the cellular accumulation of the compounds (Table 1).

Carbohydrate compounds potentially accumulate in tumors due to their high demand for glucose as a result of their upregulated glycolytic energy production. Recently, fluorescent $\mathrm{Ru}$ (arene) complexes bearing the pta or a sugar phosphite ligand were shown to accumulate in cells to a similar extent (Nazarov et al., 2012). In the present study, the most lipophilic compound 6 , according to aqueous solubility, with the biphenyl ligand and a cyclohexylidene moiety at the sugar-derived ligand was most efficiently taken up into the cell and was also the most active derivative with $\mathrm{IC}_{50}$ values in the low micromolar range. The following order of cytotoxicity was observed with regard to variation of the arene ligand in $\mathbf{1 b}, \mathbf{2 ,} \mathbf{4}$ and $\mathbf{6}$ with the identical sugar moiety: biphenyl $>$ cymene $>$ toluene $>$ benzene.

Complex 3 was chosen for DNA interaction studies with 9ethylguanine (9-EtG), and the reaction was monitored by NMR spectroscopy. Complex 3 appears to form adducts with the DNA model nucleobase 9-EtG via N7 of the guanine moiety as shown by ${ }^{1} \mathrm{H}$ NMR spectroscopy where a low-field shift from 7.85 to $8.29 \mathrm{ppm}$ was observed for $\mathrm{H} 8$ of guanine. Analysis by ${ }^{31} \mathrm{P}\left\{{ }^{1} \mathrm{H}\right\}$ NMR spectroscopy immediately after mixing 3 with 9-EtG revealed a single peak at $135.9 \mathrm{ppm}$ for the unreacted compound. Within $1 \mathrm{~h}$, two additional signals at 136.6 and 137.2 ppm appear due to the formation of diastereomers by exchange of one of the chlorido ligands with 9-EtG. However, after $24 \mathrm{~h}$ several species were formed, including signals at 93.3 and $95.1 \mathrm{ppm}$ indicative of cleavage of a P-O bond, similar to the behavior observed for related analogous complexes (Berger et al., 2008).

Furthermore, the reactivity to DNA and impact on its secondary structure was studied by determining the electrophoretic mobility of a dsDNA plasmid in cell-free experiments. However, no influence of complexes 2, 4, or $\mathbf{6}$ on the electrophoretic mobility of pBR322 plasmid DNA was observed at $r_{b}$-values (metal-to-nucleobase ratio) up to 5 within the incubation period of $2 \mathrm{~h}$. Consequently, the incubation period was increased to 4 and $6 \mathrm{~h}$ for complexes 4 and 6 , which did not lead to any observable change either, making it unlikely that the cytotoxic effect is related to DNA binding interactions.

For this reason the compounds were evaluated as inhibitors of cat B since bifunctional ruthenium(arene) compounds have been shown to be good inhibitors (Casini et al., 2008). Cathepsin $\mathrm{B}$ has been proposed to participate in metastasis, angiogenesis, and tumor progression, and therefore it is believed to be an important target for the control of tumor progression (Mohamed and Sloane, 2006). Cat B inhibitors reduce both tumor cell motility and invasiveness in vitro (Frlan and Gobec, 2006), and many palladium, rhenium, gold and ruthenium complexes, such as members of the RAPTA family and particularly RAPTA-C and RAPTA-T (Casini et al., 2008), inhibit cat B potently (Casini et al., 2008; Mura et al., 2010). Indeed, the sugar-derived phosphite based ruthenium complexes $\mathbf{1 a}, \mathbf{1} \mathbf{b}$, and $\mathbf{6}$ exhibit $\mathrm{IC}_{50}$ values in the low micromolar
Table 2 | IC $\mathrm{C}_{50}(\mu \mathrm{M})$ of $1 \mathrm{a}, 1 \mathrm{~b}$, RAPTA-C, and RAPTA-T against bovine cat $B$.

\begin{tabular}{ll}
\hline Compound & IC $_{\mathbf{5 0}}$ values/ $\boldsymbol{\mu}$ MCat $\mathbf{B}$ \\
\hline $\mathbf{1 a}$ & $1.5 \pm 0.2$ \\
$\mathbf{1 b}$ & $4.0 \pm 0.6$ \\
$\mathbf{6}$ & $8.0 \pm 0.4$ \\
\hline RAPTA-C & $2.5 \pm 0.5^{\mathrm{a}}$ \\
RAPTA-T & $1.5 \pm 0.2^{\mathrm{a}}$ \\
\hline
\end{tabular}

${ }^{a}$ From Casini et al. (2008).

range (Table 2) and thus inhibit cat $\mathrm{B}$ to an extent similar to RAPTA-T. However, no correlation with cytotoxicity data was observed.

\section{CONCLUDING REMARKS}

In this paper, we report on the synthesis and biological evaluation of $\mathrm{Ru}^{\mathrm{II}}\left(\eta^{6}\right.$-arene) complexes with carbohydrate-derived phosphorus-containing ligands. The cytotoxicity appears to be dependent on the lipophilicity, i.e., the most lipophilic compound is the most cytotoxic. Moreover, such complexes are known to exhibit certain selectivity for tumor cells over non-tumorigenic cells and are also active in cisplatin-resistant cancer cells (Berger et al., 2008; Hanif et al., 2010a). The arene ligand has little influence on the hydrolysis behavior. Binding to $9-\mathrm{EtG}$ as assayed by NMR spectroscopy suggests that some covalent interaction with DNA is possible, but no effect on the electrophoretic mobility and therewith the secondary structure of plasmid DNA was observed. Studies on the inhibition of cathepsin B revealed that the carbohydrate compounds are potent inhibitors comparable to the metastasis inhibitors RAPTA-C and RAPTA-T, which appear to interact with histone proteins of the nucleosome core particle (Wu et al., 2011). However, further experiments are required to draw unambiguous conclusions on the mode of action of these compounds. Overall, carbohydrate-based metal(arene) complexes have demonstrated promising antiproliferative activity in in vitro assays, but only in vivo experiments will give deeper insight into the potential of these compounds as anticancer drugs.

\section{ACKNOWLEDGMENTS}

We thank the Higher Education Commission of Pakistan (Muhammad Hanif), the Austrian Exchange Service (ÖAD), the Hochschuljubiläumsstiftung Vienna, the FFG - Austrian Research Promotion Agency (811591), the Austrian Council for Research and Technology Development (IS526001), COST D39 and CM1105 and the Austrian Science Fund for financial support. This research was supported by a Marie Curie Intra European Fellowship within the 7th European Community Framework Programme project 220890-SuRuCo and Russian Foundation for Basic Research 13-03-00513 and 13-03-12460 (Alexey A. Nazarov). We gratefully acknowledge Michaela Hejl for performing some of the in vitro anticancer assays and Prof. Markus Galanski for recording the 2D NMR spectra. 


\section{REFERENCES}

Aird, R. E., Cummings, J., Ritchie, A. A., Muir, M., Morris, R. E., Chen, H., et al. (2002). In vitro and in vivo activity and cross resistance profiles of novel ruthenium(II) organometallic arene complexes in human ovarian cancer. $\mathrm{Br}$. J. Cancer 86, 1652-1657. doi: 10.1038/sj.bjc.6600290

Bennett, M. A., Huang, T. N., Matheson, T. W., and Smith, A. K. (1982). $\quad\left(\eta^{6}\right.$-Hexa methylbenzene)ruthenium complexes. Inorg. Synth. 21, 74-78. doi: 10.1002/9780470132524.ch16

Bennett, M. A., and Smith, A. K. (1974). Arene ruthenium(II) complexes formed by dehydrogenation by cyclohexadienes with ruthenium(III) trichloride. J. Chem. Soc. Dalton Trans. 2, 233-241. doi: $10.1039 / \mathrm{dt} 9740000233$

Berger, I., Hanif, M., Nazarov, A. A., Hartinger, C. G., John, R. O., Kuznetsov, M. L., et al. (2008). In vitro anticancer activity and biologically relevant metabolization of organometallic ruthenium complexes with carbohydrate-based ligands. Chem. Eur. J. 14, 9046-9057. doi: 10.1002/chem. 200801032

Casini, A., Gabbiani, C., Sorrentino, F., Rigobello, M. P., Bindoli, A., Geldbach, T. J., et al. (2008). Emerging Protein Targets for Anticancer Metallodrugs: Inhibition of Thioredoxin Reductase and Cathepsin B by Antitumor Ruthenium(II)-Arene Compounds. J. Med. Chem. 51, 6773-6781. doi: 10.1021/jm8006678

Chen, H., Parkinson, J. A., Morris, R. E., and Sadler, P. J. (2003). Highly Selective Binding of Organometallic Ruthenium Ethylenediamine Complexes to Nucleic Acids: Novel Recognition Mechanisms. J. Am. Chem. Soc. 125, 173-186. doi: $10.1021 / \mathrm{ja} 027719 \mathrm{~m}$

Dyson, P. J. (2007). Systematic design of a targeted organometallic antitumor drug in pre-clinical development. Chimia 61, 698-703. doi: 10.2533/chimia. 2007.698

Egger, A. E., Rappel, C., Jakupec, M. A., Hartinger, C. G., Heffeter, P., and Keppler, B. K. (2009). Development of an experimental protocol for uptake studies of metal compounds in adherent tumor cells. J. Anal. At. Spectrom. 24, 51-61. doi: 10.1039/b810481f

Fricker, S. P. (2010). Cysteine proteases as targets for metal-based drugs. Metallomics 2, 366-377. doi: $10.1039 / \mathrm{b} 924677 \mathrm{k}$
Frlan, R., and Gobec, S. (2006). Inhibitors of cathepsin B. Curr. Med. Chem. 13, 2309-2327. doi: 10.2174/092986706777935122

Gasser, G., Ott, I., and Metzler-Nolte, N. (2011). Organometallic anticancer compounds. J. Med. Chem. 54, 3-25. doi: 10.1021/jm100020w

Gottschaldt, M., and Schubert, U. S. (2009). Prospects of metal complexes peripherally substituted with sugars in biomedicinal applications. Chem. Eur. J. 15, 1548-1557. doi: 10.1002/chem. 200802013

Habtemariam, A., Melchart, M., Fernandez, R., Parsons, S., Oswald, I. D. H., Parkin, A., et al. (2006). Structure-Activity Relationships for Cytotoxic Ruthenium(II) Arene Complexes Containing, N, N-, N, $\mathrm{O}-$, and $\mathrm{O}$, O-Chelating Ligands. J. Med. Chem. 49, 6858-6868. doi: $10.1021 / \mathrm{jm} 060596 \mathrm{~m}$

Hanif, M., Meier, S. M., Kandioller, W., Bytzek, A., Hejl, M., Hartinger, C. G., et al. (2011). From hydrolytically labile to hydrolytically stable $\mathrm{Ru}^{\mathrm{II}}$ arene anticancer complexes with carbohydrate-derived co-ligands. J. Inorg. Biochem. 105, 224-231. doi: 10.1016/j.jinorgbio.2010.10.004

Hanif, M., Nazarov, A. A., and Hartinger, C. G. (2012a). Synthesis of $\left[\mathrm{Ru}^{\mathrm{II}}\left(\eta^{6}-\right.\right.$ p-cymene $\left.)\left(\mathrm{PPh}_{3}\right)(\mathrm{L}) \mathrm{Cl}\right] \mathrm{PF}_{6}$ complexes with carbohydrate-derived phosphites, imidazole or indazole co-ligands. Inorg. Chim. Acta 380, 211-215. doi: 10.1016/j.ica.2011. 10.007

Hanif, M., Nazarov, A. A., Legin, A., Groessl, M., Arion, V. B., Jakupec, M. A., et al. (2012b). Maleimidefunctionalised organoruthenium anticancer agents and their binding to thiol-containing biomolecules. Chem. Commun. 48, 1475-1477. doi: $10.1039 / \mathrm{clcc} 14713 \mathrm{~g}$

Hanif, M., Nazarov, A. A., Hartinger, C. G., Kandioller, W., Jakupec, M. A., Arion, V. B., et al. (2010a). Osmium(II)- versus ruthenium(II)-arene carbohydratebased anticancer compounds: similarities and differences. Dalton Trans. 39, 7345-7352. doi: 10.1039/c003085f

Hanif, M., Schaaf, P., Kandioller, W., Hejl, M., Jakupec, M. A., Roller, A., et al. (2010b). Influence of the arene ligand and the leaving group on the anticancer activity of (thio)maltol ruthenium(II)-( $\eta^{6}$ arene) complexes. Aust. J. Chem. 63, 1521-1528. doi: 10.1071/CH10232

Hartinger, C. G., and Dyson, P. J. (2009). Bioorganometallic Chemistry - From Teaching
Paradigms to Medicinal Application. Chem. Soc. Rev. 38, 391-401. doi: 10.1039/b707077m

Hartinger, C. G., Metzler-Nolte, N., and Dyson, P. J. (2012). Challenges and Opportunities in the Development of Organometallic Anticancer Drugs. Organometallics 31, 5677-5685. doi: 10.1021/om300373t

Hartinger, C. G., Nazarov, A. A., Ashraf, S. M., Dyson, P. J., and Keppler, B. K. (2008). Carbohydrate-Metal Complexes and their Potential as Anticancer Agents. Curr. Med. Chem. 15, 2574-2591. doi: 10.2174/092986708785908978

Kandioller, W., Kurzwernhart, A., Hanif, M., Meier, S. M., Henke, H., Keppler, B. K., et al. (2011). Pyrone derivatives and metals: From natural products to metal-based drugs. J. Organomet. Chem. 696, 999-1010. doi: 10.1016/j.jorganchem.2010.11.010

Kochetkov, N. K., Nifant'ev, E. E., Koroteev, M. P., Zhane, Z. K., and Borisenko, A. A. (1976). Synthesis and stereochemistry of 6-deoxy6-halo-D-glucofuranose cyclic phosphates. Carbohydr. Res. 47, 221-231. doi: 10.1016/S00086215(00)84187-7

Mendoza-Ferri, M. G., Hartinger, C. G., Nazarov, A. A., Eichinger, R. E., Jakupec, M. A., Severin, K., et al. (2009). Influence of the arene ligand, the number and type of metal centers, and the leaving group on the in vitro antitumor activity of polynuclear organometallic compounds. Organometallics 28, 6260-6265. doi: 10.1021/om900715j

Mohamed, M. M., and Sloane, B. F. (2006). Cysteine cathepsins: multifunctional enzymes in cancer. Nat. Rev. Cancer 6, 764-775. doi: 10.1038/nrc1949

Mura, P., Camalli, M., Casini, A., Gabbiani, C., and Messori, L. (2010). Trans-cis-cis$\left[\mathrm{RuCl}_{2}(\mathrm{DMSO})_{2}\right.$ (2-amino-5methyl-thiazole $)_{2}$ ], (PMRu52), a novel ruthenium(II) compound acting as a strong inhibitor of cathepsin B. J. Inorg. Biochem. 104, 111-117. doi: 10.1016/j.jinorgbio.2009.10.002

Nazarov, A. A., Risse, J., Ang, W. H., Schmitt, F., Zava, O., Ruggi, A., et al. (2012). AnthraceneTethered Ruthenium(II) Arene Complexes as Tools To Visualize the Cellular Localization of Putative Organometallic Anticancer Compounds. Inorg. Chem. 51, 3633-3639. doi: 10.1021/ic202530j
Peacock, A. F. A., and Sadler, P. J. (2008). Medicinal organometallic chemistry: designing metal arene complexes as anticancer agents. Chem. Asian J. 3, 1890-1899. doi: 10.1002/asia.200800149

Scolaro, C., Bergamo, A., Brescacin, L., Delfino, R., Cocchietto, M., Laurenczy, G., et al. (2005). In vitro and in vivo evaluation of ruthenium(II)Arene PTA complexes. J. Med. Chem. 48, 4161-4171. doi: $10.1021 / \mathrm{jm} 050015 \mathrm{~d}$

Scolaro, C., Hartinger, C. G., Allardyce, C. S., Keppler, B. K., and Dyson, P. J. (2008). Hydrolysis study of the bifunctional antitumor compound RAPTA-C, $\left[\mathrm{Ru}\left(\eta^{6}\right.\right.$ p-cymene) $\mathrm{Cl}_{2}$ (pta)]. J. Inorg. Biochem. 102, 1743-1748. doi: 10.1016/j.jinorgbio.2008.05.004

Wu, B., Ong, M. S., Groessl, M., Adhireksan, Z., Hartinger, C. G., Dyson, P. J., et al. (2011). A Ruthenium Antimetastasis Agent Forms Specific Histone Protein Adducts in the Nucleosome Core. Chem. Eur. J. 17, 3562-3566. doi: 10.1002/chem. 201100298

Conflict of Interest Statement: The authors declare that the research was conducted in the absence of any commercial or financial relationships that could be construed as a potential conflict of interest.

Received: 31 July 2013; accepted: 10 October 2013; published online: 31 October 2013.

Citation: Hanif M, Meier SM, Nazarov AA, Risse J, Legin A, Casini A, Jakupec $M A$, Keppler $B K$ and Hartinger $C G$ (2013) Influence of the $\pi$-coordinated arene on the anticancer activity of ruthenium(II) carbohydrate organometallic complexes. Front. Chem. 1:27. doi: 10.3389/fchem.2013.00027

This article was submitted to Inorganic Chemistry, a section of the journal Frontiers in Chemistry.

Copyright (c) 2013 Hanif, Meier, Nazarov, Risse, Legin, Casini, Jakupec, Keppler and Hartinger. This is an open-access article distributed under the terms of the Creative Commons Attribution License (CC BY). The use, distribution or reproduction in other forums is permitted, provided the original author(s) or licensor are credited and that the original publication in this journal is cited, in accordance with accepted academic practice. No use, distribution or reproduction is permitted which does not comply with these terms. 